\title{
Low Cogging Torque and High Efficient 3-Phase Spindle Motors by Reshaping Magnetic Circuit Profiles
}

\author{
Kuo-Chi Chiu, Der-Ray Huang, and Han-Ping D. Shieh
}

\begin{abstract}
The dynamic characteristics of a 3-phase spindle motor with 12-poles and 9-slots can be improved by reshaping the magnetic circuit profiles. The stator cores were designed with different ratios of $x / y$ where $x$ is the gap angle between 2-slots and $y$ is the expanded angle of a slot. Experiment and finite element analyses (FEA) results show that $x / y$ ratio of $1 / 2.5$ is an optimal design in achieving dynamic performance for DVD drives applications.
\end{abstract}

Index Terms-Back-emf, cogging torque, DVD drives, FEA, finite element analysis, rise time, runout, spindle motor.

\section{INTRODUCTION}

$\mathbf{T}$ HE BRUSHLESS spindle motors are widely used for DVD applications. The read/write performance for DVD drives is highly dependent on the dynamic characteristics of the spindle motors which have to satisfy the specifications for vibration, runout, running current, cogging torque, running torque, and efficiency, etc. These dynamic performances are very sensitive to the magnetic circuit profiles between the rotor and stator in a spindle motor, because the magnetic flux leakage and interaction force are highly dependent on the magnetic circuit. In this paper, both experiment and analyzes on different $x / y$ values were investigated, where $x$ is the gap angle between 2-slots and y is the expanded angle of a slot, and an optimal design for a spindle motor in achieving tight requirements for DVD drives was obtained.

\section{EXPERIMENT}

The main structure of rotor includes a turntable, shaft, yoke, and magnet, and the basic elements of stator are combined with a stator core, FPCB (Floppy Printed Circuit Board), sleeve bearing, and support plate, as shown in Fig. 1. The same rotor is used for the different experiments and the stator is adjusted with different $x / y$ values [1]-[4]. The stator core was designed with different ratios of $x / y$. Each stator core was stacked by 15 pieces of silicon steel with thickness of $0.35 \mathrm{~mm}$. The coil with diameter of $0.17 \mathrm{~mm}$ was wound with 50 turns for each

Manuscript received October 13, 2000.

K.-C. Chiu is with the Institute of Electro-Optic Engineering, National Chiao Tung University, Hsinchu 300, Taiwan, R.O.C. He is also with Bldg. 78, J010, OES/ITRI, Chutung, Hsinchu 310, Taiwan, R.O.C.

D.-R. Huang is with Bldg. 78, J010, OES/ITRI, Chutung, Hsinchu 310, Taiwan, R.O.C.

H.-P. D. Shieh is with the Institute of Electro-Optic Engineering, National

Chiao Tung University, Hsinchu 300, Taiwan, R.O.C.

Publisher Item Identifier S 0018-9464(01)07102-3.

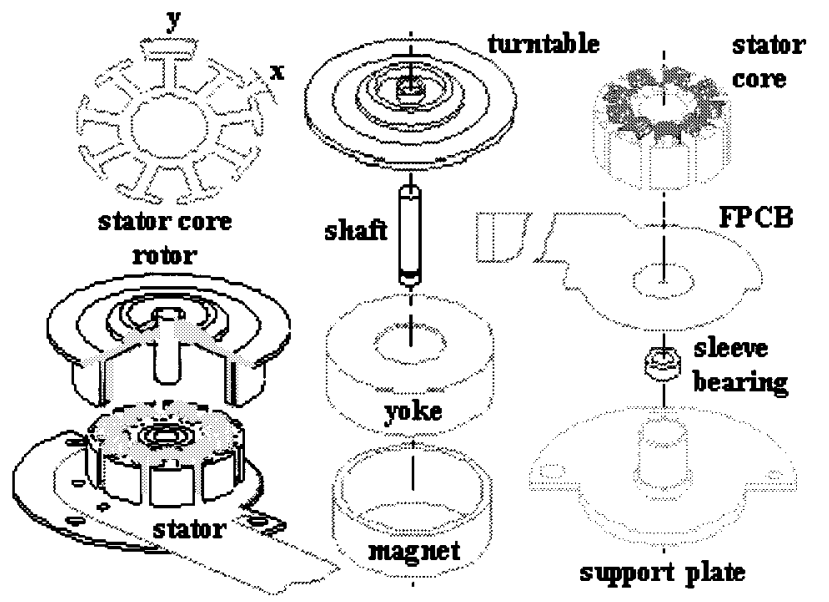

Fig. 1. Structure of a spindle motor and the definition of $x$ and $y$ in the stator core.

TABLE I

SIX SETS OF $x / y$ AND THEIR RESISTANCE OF COILS

\begin{tabular}{|c|r|r|c|c|c|}
\hline Motor & $\mathrm{x}$ & $\mathrm{Y}$ & $\mathrm{x}+\mathrm{y}$ & $\mathrm{x} / \mathrm{y}$ & Resistance $(\Omega)$ \\
\hline$\# 1$ & $20^{\circ}$ & $20^{\circ}$ & $40^{\circ}$ & $1 / 1.0$ & 4.05 \\
\hline$\# 2$ & $16^{\circ}$ & $24^{\circ}$ & $40^{\circ}$ & $1 / 1.5$ & 3.90 \\
\hline$\# 3$ & $13.33^{\circ}$ & $26.67^{\circ}$ & $40^{\circ}$ & $1 / 2.0$ & 3.96 \\
\hline$\# 4$ & $11.43^{\circ}$ & $28.57^{\circ}$ & $40^{\circ}$ & $1 / 2.5$ & 4.01 \\
\hline$\# 5$ & $10^{\circ}$ & $30^{\circ}$ & $40^{\circ}$ & $1 / 3.0$ & 3.96 \\
\hline$\# 6$ & $8^{\circ}$ & $32^{\circ}$ & $40^{\circ}$ & $1 / 4.0$ & 3.97 \\
\hline
\end{tabular}

slot. The magnet made of $\mathrm{Nd}-\mathrm{Fe}-\mathrm{B}$ was magnetized in radial direction with 12-poles. The outer diameter, inner diameter, and thickness of the magnet are 22.4, 20.1, and $6.0 \mathrm{~mm}$, respectively. The summation of $x$ and $y$ is fixed at 40 degrees. Table I lists the six ratios of $x / y$ and their resistance. The dynamic characteristics including cogging torque, runout, vibration, running current, rise time, and torque constant were measured by using a torque meter to evaluate the performance of the spindle motor.

\section{RESUlTS AND DisCUSSION}

Optical disks need to be stable while the pick-up head reads the data on the disk. In order to meet the specifications of tracking and focusing for pick-up head operation, the dynamic runout should be within $0.03 \mathrm{~mm}$. Runout as functions of 


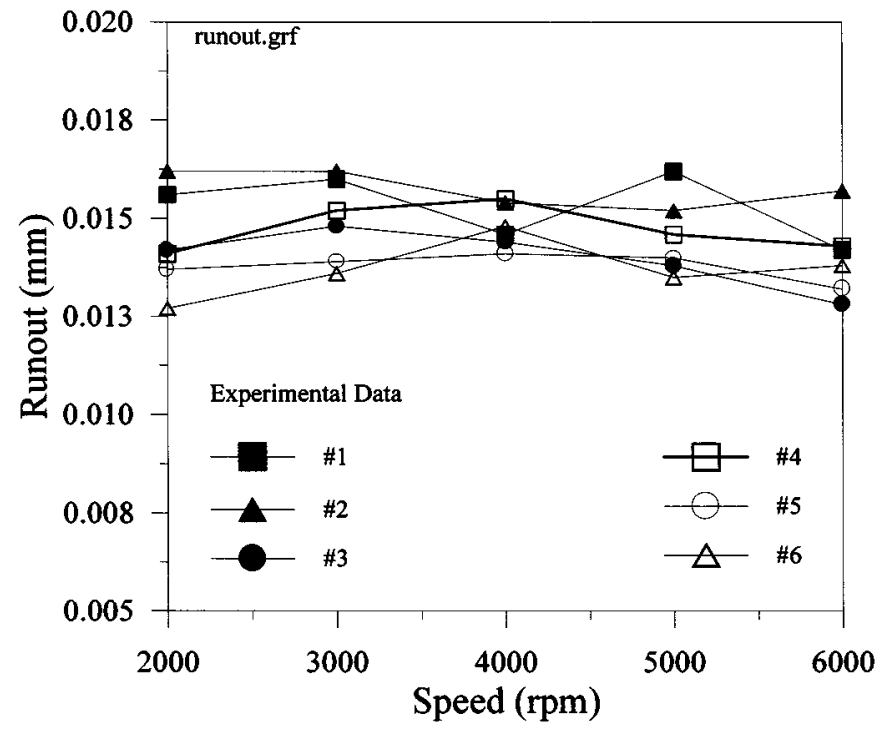

Fig. 2. Dynamic runout of spindle motor as functions of the rotational speed and $x / y$ ratio.

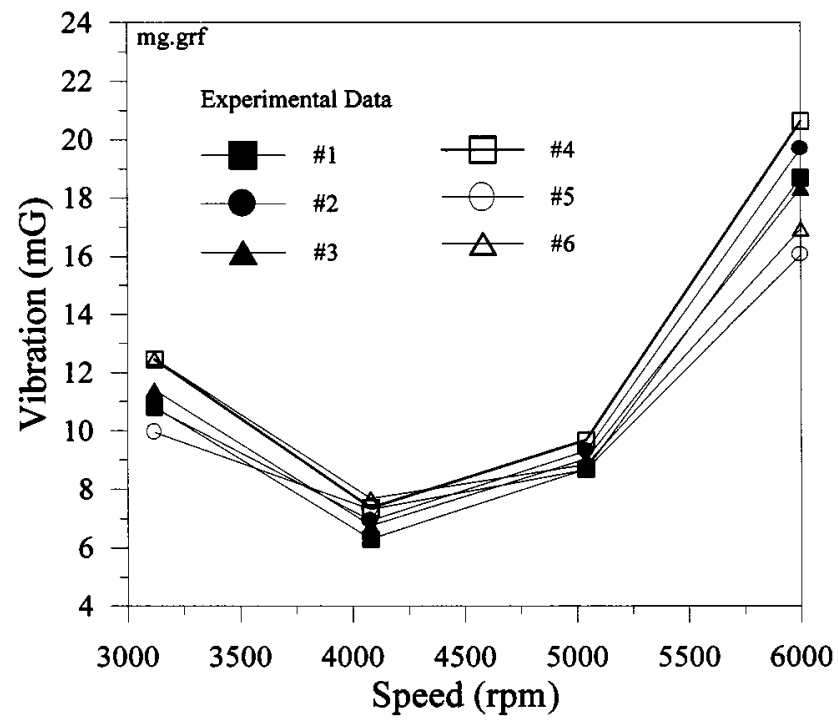

Fig. 3. Vibration of spindle motor as functions of rotational speed and $x / y$ ratio.

rotational speed of spindle motors of six $x / y$ ratios is shown in Fig. 2. The dynamic runout should be insensitive with the rotational speed, or it is hard to control the tracking and focusing. Clearly, the dynamic runout of the spindle motor designed with all six ratios can be adjusted and all of them satisfy the specification of DVD applications of less than $0.03 \mathrm{~mm}$.

The vibration of the spindle motor increases significantly as rotational speed increases. Fig. 3 shows the vibration as functions of the rotational speed of the spindle motors and $x / y$ ratio. The high vibration value at $3000 \mathrm{rpm}$ is mainly due to a resonance mode. The noise of drives is always caused by the vibration, which should be minimized. The maximum vibration with $21 \mathrm{mG}$ occurs at $6000 \mathrm{rpm}$. (G : unit of gravity). All of motors are within the vibration specification of less than $50 \mathrm{mG}$, even at $6000 \mathrm{rpm}$.

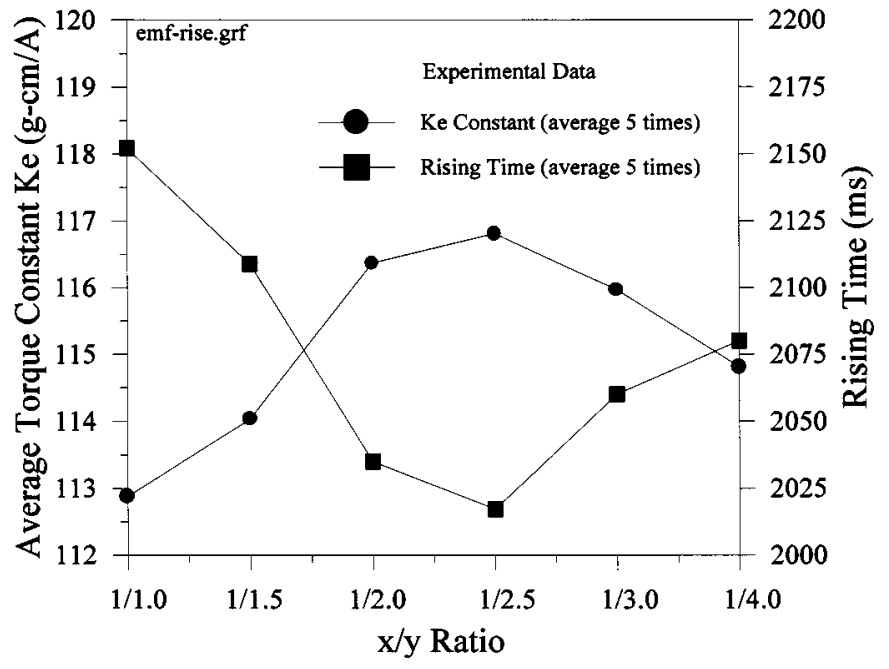

Fig. 4. The average torque constant Ke and rise time as a function of $x / y$ ratio.

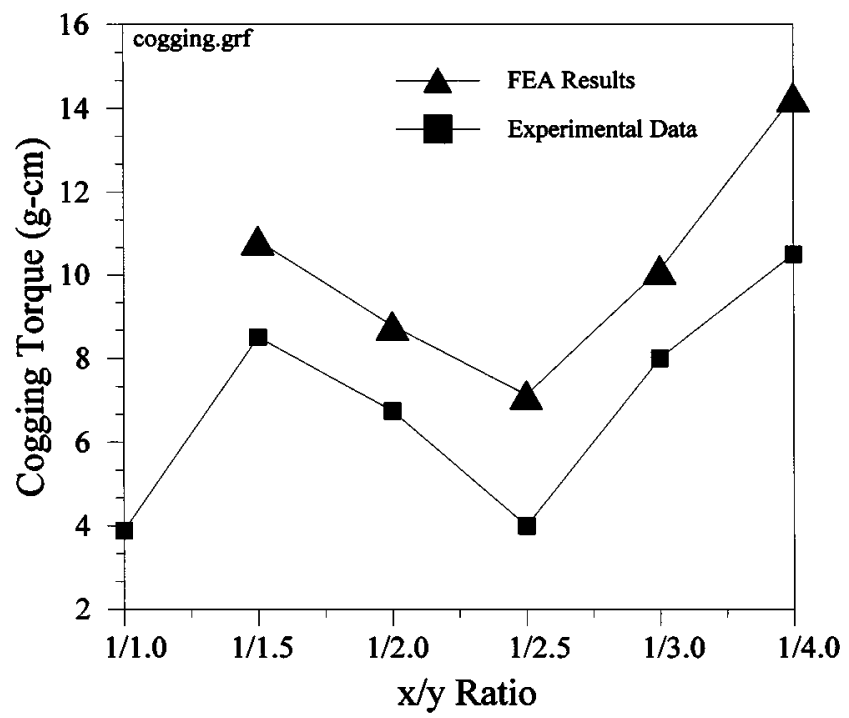

Fig. 5. The cogging torque of spindle motor as a function of $x / y$ ratio measured experimentally and derived analytically.

The rise time is defined as the time interval needed to accelerate from 1000 to $6000 \mathrm{rpm}$. Rise time is inversely proportional to the average torque constant $\mathrm{Ke}$, for all six $x / y$ ratios spindle motors as shown in Fig. 4 measured experimentally. Spindle motors can be driven with a small running current at a higher torque constant and achieve a fast access time with a small rise time. In our experiment, the stator core designed with a $x / y$ ratio of $1 / 2.5$ possesses the shortest rise time and the maximum torque constant. A comparison of these two curves show that motor with $x / y$ ratio of $1 / 2.5$ is the most powerful one.

The cogging torque of a spindle motor greatly affects the noise and vibration characteristics. It is highly undesirable to start a spindle motor with a big cogging torque which needs a high starting current. A good estimation by finite element analyses (FEA) can be used to analyze the cogging torque of spindle motor. First, we acquired the energy at the different angle of $E(\theta)$. Then, cogging torque is $T(\theta)=E^{\prime}(\theta)$. Therefore, the cogging torque of each $x / y$ ratio could be obtained. 


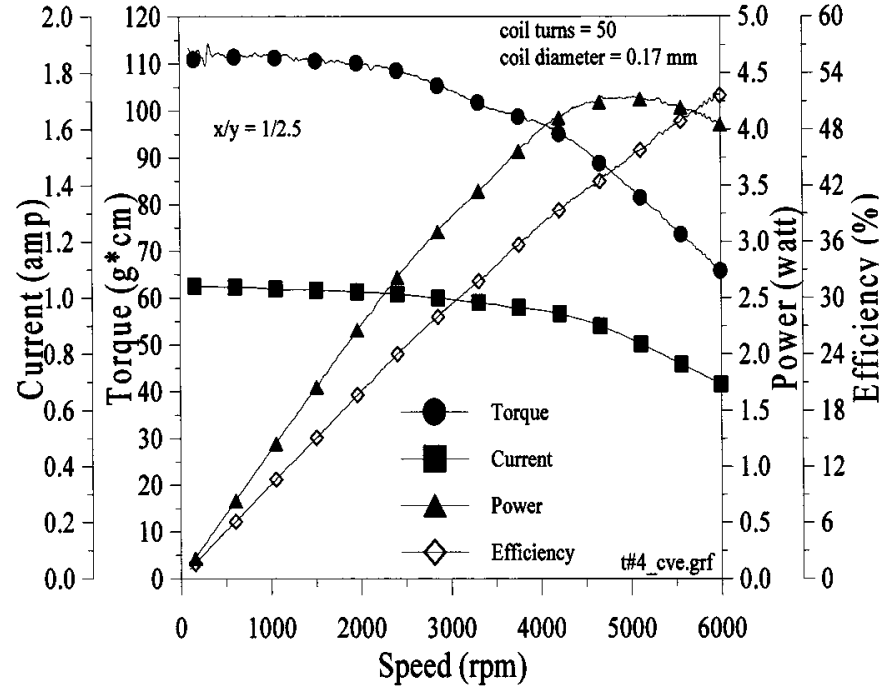

Fig. 6. The characteristic curves of spindle motor with $x / y$ ratio of $1 / 2.5$.

The cogging torque dependence on the ratios of $x / y$ is depicted in Fig. 5. The FEA results are agreed with the experimental data. The ratio of $1 / 2.5$ has the lowest cogging torque among other $x / y$ ratios.

Motors with the ratio of $1 / 1$ and $1 / 2.5$ have lower cogging torque whose average torque constants are 112.88 and $115.71 \mathrm{~g}-\mathrm{cm} / \mathrm{A}$, respectively. However, motor of $\mathrm{x} / \mathrm{y}$ ratio of $1 / 1$ has the highest rise time. Therefore, a stator core with the ratio of $1 / 2.5$ is the best design for spindle motor in our experiment. To further analyze the spindle motor with stator core $x / y$ ratio of $1 / 2.5$ running current, torque, power and efficiency as a function of rotational speed is plotted in Fig. 6. The maximum values of current, torque, power and efficiency are 1.01 Amp, $110 \mathrm{~g}-\mathrm{cm}, 4.48$ watt and $51.5 \%$, respectively. Moreover, all the above parameters of the spindle motors up to $6000 \mathrm{rpm}$ are within the design specifications for pick-up operations.

\section{CONCLUSIONS}

The spindle motor with the ratio of $1 / 2.5$ was found experimentally and analytically to be the best design in its dynamic characteristics for optical pick-up head operations. The stator core adjusted with the gap angle $x$ of $11.43^{\circ}$ and slot angle $\mathrm{y}$ of $28.57^{\circ}$ is an optimal construction. The spindle motor has the highest torque constant and the lowest running time and cogging torque, enable the spindle motor to function effectively at a low running current, fast access time, and low starting current, in addiction to small runout and vibration. The above performances are essential for pick-up head in high-speed tracking and focusing for DVD drive to read data reliably from the disks.

\section{REFERENCES}

[1] I. H. Park, B. T. Lee, and S. Y. Lahn, "Pole shape optimization for reduction of cogging torque by sensitivity analysis," COPEL, vol. 9, no. 5, pp. 111-114, 1990.

[2] D. R. Huang, T. F. Ying, S. J. Wang, C. M. Zhou, Y. K. Lin, K. W. Su, and C. I. Hsu, "Cogging torque reduction of a single-phase brushless DC motor," IEEE Trans. Magn., vol. 34, pp. 2075-2077, 1998.

[3] Y. D. Yao, D. R. Huang, J. C. Wang, S. J. Wang, T. F. Ying, and D. Y. Chiang, "Study of a high efficiency and low cogging torque spindle motor," IEEE Trans. Magn., vol. 34, pp. 465-467, 1998.

[4] D. R. Huang, C. Y. Fan, S. J. Wang, H. P. Pan, T. F. Ying, C. M. Chao, and E. G. Lean, "A new type single-phase spindle motor for HDD and DVD," IEEE Trans. Magn., vol. 35, pp. 839-844, 1999. 